\title{
Activity-Dependent Metaplasticity of Inhibitory and Excitatory Synaptic Transmission in the Lamprey Spinal Cord Locomotor Network
}

\author{
David Parker and Sten Grillner \\ Nobel Institute for Neurophysiology, Department of Neuroscience, Karolinska Institute, S-17177, Stockholm, Sweden
}

Paired intracellular recordings have been used to examine the activity-dependent plasticity and neuromodulator-induced metaplasticity of synaptic inputs from identified inhibitory and excitatory interneurons in the lamprey spinal cord. Trains of spikes at $5-20 \mathrm{~Hz}$ were used to mimic the frequency of spiking that occurs in network interneurons during NMDA or brainstemevoked locomotor activity. Inputs from inhibitory and excitatory interneurons exhibited similar activity-dependent changes, with synaptic depression developing during the spike train. The level of depression reached was greater with lower stimulation frequencies. Significant activity-dependent depression of inputs from excitatory interneurons and inhibitory crossed caudal interneurons, which are central elements in the patterning of network activity, usually developed between the fifth and tenth spikes in the train. Because these interneurons typically fire bursts of up to five spikes during locomotor activity, this

Fast synaptic transmission plays a major role in patterning the activity of neural networks underlying motor and cognitive tasks (Singer, 1993; Calabrese, 1995). Although short and long-term activity-dependent plasticity of synaptic transmission has been analyzed extensively in relation to learning and memory (Milner et al., 1998), little attention has focused on its role in patterning the output of rhythmic neural networks.

Locomotion in vertebrates is generated by rhythmically active spinal cord networks (see Kiehn et al., 1997). In the lamprey, the types and properties of neurons in the locomotor network are known in some detail (Buchanan and Grillner, 1987). As in other vertebrates (see Kiehn et al., 1997), symmetrical networks on each side of the lamprey spinal cord are coupled through glycinergic reciprocal inhibitory connections (Buchanan, 1982). The strength of this reciprocal inhibitory input is an important factor in determining the frequency of network activity (Grillner and Wallén, 1980; Hellgren et al., 1992). An increase in reciprocal inhibition slows the frequency of network activity by delaying the activation of the contralateral network, whereas a reduction increases the frequency of network activity by allowing the contralateral network to become active sooner (Hellgren et al., 1992). Excitatory drive at the segmental level is mediated by glutama-

Received Oct. 20, 1998; revised Dec. 14, 1998; accepted Dec. 16, 1998.

This work was supported by grants from the Swedish Brain Foundation and the Swedish Medical Research Council $(12589,3026)$, and by funds from the Karolinska Institute. Jeanette Hellgren, Erik Svensson, and Jesper Tegnér provided constructive criticism of this manuscript.

Correspondence should be addressed to David Parker, Nobel Institute for Neurophysiology, Department of Neuroscience, Karolinska Institute, S-17177, Stockholm, Sweden.

Copyright (C) 1999 Society for Neuroscience $0270-6474 / 99 / 191647-10 \$ 05.00 / 0$ activity-dependent plasticity will presumably not contribute to the patterning of network activity. However, in the presence of the neuromodulators substance $\mathrm{P}$ and $5-\mathrm{HT}$, significant activitydependent metaplasticity of these inputs developed over the first five spikes in the train. Substance $P$ induced significant activity-dependent depression of inhibitory but potentiation of excitatory interneuron inputs, whereas 5-HT induced significant activity-dependent potentiation of both inhibitory and excitatory interneuron inputs. Because these metaplastic effects are consistent with the substance $\mathrm{P}$ and 5 - HT-induced modulation of the network output, activity-dependent metaplasticity could be a potential mechanism underlying the coordination and modulation of rhythmic network activity.

Key words: synaptic plasticity; metaplasticity; spinal cord; lamprey; neuropeptide; substance P; 5-HT

tergic interneurons (Buchanan and Grillner, 1987). A general increase in excitatory drive to the network, either experimentally or in computer simulations, results in an increase in the frequency of network activity (Brodin et al., 1985; Hellgren et al., 1992).

Here, the activity-dependent synaptic plasticity of inputs from four types of identified network interneurons in the lamprey have been examined: glycinergic inhibitory and glutamatergic excitatory crossed caudal interneurons (CCINs; Buchanan, 1982), glycinergic lateral interneurons (LINs; Buchanan, 1982), and glutamatergic excitatory interneurons (EINs; Buchanan and Grillner, 1987). Inhibitory CCINs and EINs mediate reciprocal inhibition and excitatory drive, respectively (Buchanan, 1982; Buchanan and Grillner, 1987), and are thus important elements in the regulation of network activity. Because the roles of these interneurons are known, the activity-dependent plasticity of their inputs can be directly related to effects on the coordination of network activity.

Activity-dependent plasticity is also plastic, an effect termed "metaplasticity" (Abraham and Bear, 1996). Although this term was introduced to describe the effects of previous activity on the induction or expression of synaptic plasticity, metaplastic effects can also occur in the presence of neuromodulators (Sombati and Hoyle, 1984; Fisher et al., 1997). To determine whether network modulation can be associated with the metaplasticity of interneuron inputs, the effects of the neuromodulators substance $\mathrm{P}$ and 5-HT, which have been studied in detail on the locomotor network (Harris-Warrick and Cohen, 1985; Wallén et al., 1989; Parker and Grillner, 1998; Parker et al., 1998), were examined. The results of this study suggest little contribution of activitydependent plasticity to the patterning of network activity under control conditions, but that substance $\mathrm{P}$ and 5-HT induced 
activity-dependent metaplasticity could contribute to the modulation of network activity.

\section{MATERIALS AND METHODS}

Adult male and female lampreys (Lampetra fluviatilis) were used in all experiments. Animals were anesthetized with tricaine methanesulphonate (MS-222; Sandoz, Basel, Switzerland), and the spinal cord and notochord were removed. The spinal cord was isolated and placed ventral side up in a Sylgard-lined (Sikema, Stockholm, Sweden) chamber and superfused with Ringer's solution containing (in $\mathrm{mm}$ ): $138 \mathrm{NaCl}, 2.1$ $\mathrm{KCl}, 1.8 \mathrm{CaCl}_{2}, 1.2 \mathrm{MgCl}_{2}, 4$ glucose, 2 HEPES, and 0.5 L-glutamine, which was bubbled with $\mathrm{O}_{2}$. The chamber was kept at a temperature of $8-12^{\circ} \mathrm{C}$

Intracellular recordings were made from the cell bodies of spinal cord neurons using thin-walled micropipettes filled with $3 \mathrm{M}$ potassium acetate and $0.1 \mathrm{M}$ potassium chloride. An Axoclamp 2A amplifier (Axon Instruments, Foster City, CA) was used for voltage recording and current injection. Data were acquired and stored on a computer using an analogto-digital interface (Digidata 1200; Axon Instruments) and Axon Instruments software (pClamp 6). Neurons were identified according to previously established criteria (Buchanan, 1993). Except where stated, motor neurons were used as the postsynaptic target cells. These were identified by recording orthodromic spikes in the adjacent ventral root after suprathreshold current injection into their somata. Inhibitory or excitatory CCINs were identified by their ability to elicit monosynaptic IPSPs or EPSPs, respectively, in contralateral motor neurons, and by recording orthodromic spikes on the contralateral caudal region of the spinal cord, at least ten segments from the presumed CCIN. EINs were identified by their ability to elicit monosynaptic EPSPs in ipsilateral motor neurons. Lateral interneurons were identified by their shape and position in the spinal cord and by recording orthodromic spikes on the ipsilateral caudal region of the spinal cord at least ten segments from the presumed LIN. CCINs, LINs, and EINs were recorded in either the same segment or at most one segment rostral to the postsynaptic neuron. Monosynaptic EPSPs and IPSPs were identified by their ability to follow reliably and with constant latency after presynaptic stimulation at $20 \mathrm{~Hz}$.

During NMDA and brainstem stimulation-evoked locomotor activity, network interneurons fire between two to five spikes at frequencies of 5-30 Hz, depending on the burst duration (Buchanan and Cohen, 1982; Buchanan and Kasicki, 1995), although spiking for up to $1 \mathrm{sec}$ can occur during slower network activity (D. Parker, unpublished data). In this study, intracellular stimulation of the presynaptic neuron with trains of twenty spikes at frequencies of $5-20 \mathrm{~Hz}$ was used to approximate physiological activity. The highest frequency used was $20 \mathrm{~Hz}$, because at this frequency the PSPs had largely decayed before the onset of the next PSP in the train, thus facilitating the measurement of the amplitude of individual PSPs. Spike trains were evoked at 1 min intervals. Recovery of the activity-dependent changes was examined by triggering presynaptic spikes at $1 \mathrm{~Hz}$ for $1-4 \mathrm{sec}$ after the end of the spike train. When excitatory inputs were examined, $5 \mu \mathrm{M}$ strychnine was added to the Ringer's solution to block glycinergic IPSPs. When examining IPSPs, CNQX $(10 \mu \mathrm{M})$ and APV $(100 \mu \mathrm{M})$ were used to block glutamatergic inputs. Only postsynaptic neurons with a low level of spontaneous synaptic inputs were used, to minimize the occurrence of spontaneous inputs during the spike train. Substance P can increase synaptic inputs and induce membrane potential oscillations in motor neurons and network interneurons (Parker and Grillner, 1998). Because the synaptic input and oscillations are cyclical, with a period of several minutes, trials were only performed when synaptic inputs to the cell were low. In all cases, the membrane potential in control and in the presence of substance P or 5-HT was kept constant by injecting depolarizing or hyperpolarizing current using single-electrode current clamp. The output of the sample and hold amplifier was monitored continuously to ensure complete voltage settling.

Drugs were applied to the bath using a peristaltic pump. A $1 \mu \mathrm{M}$ concentration of substance $\mathrm{P}$ was used in all experiments, because this concentration has been shown to have significant long-lasting effects on the locomotor network (Parker and Grillner, 1998; Parker et al., 1998). A $10 \mu \mathrm{M}$ concentration of 5-HT was used, because this concentration has been shown to modulate sensory and reticulospinal synaptic transmission (Buchanan and Grillner, 1991; El Manira et al., 1997). Substance P and 5-HT were applied for $10 \mathrm{~min}$. Two or three trials were performed at each frequency in control and in the presence of the modulator. $n$ numbers in the text refer to the number of pairs examined. The different trials for each pair were averaged. No more than two pairs were examined in a single piece of spinal cord. When modulators were applied, only one pair was examined in each piece of cord. Values in the text refer to the EPSP or IPSP amplitude as percent of control. Unless stated otherwise, statistical significance of effects seen with individual stimulation frequencies, either in control or in the presence of neuromodulators, was examined using a two-tailed paired $t$ test. A one-way ANOVA was used to examine the significance of effects between different stimulation frequencies, and a Tukey test was used for post hoc comparisons of group means.

\section{RESULTS}

\section{Activity-dependent plasticity of interneuron inputs}

During NMDA and brainstem stimulation-evoked locomotor activity, network interneurons fire between two to five spikes at frequencies of 5-30 Hz, depending on the burst duration (Buchanan and Cohen, 1982; Buchanan and Kasicki, 1995). A train of twenty stimuli applied to inhibitory CCINs at frequencies of 5-20 Hz resulted in frequency-dependent effects on the amplitude of the monosynaptic IPSP in contralateral motor neurons (Fig. 1). At $5 \mathrm{~Hz}$, depression developed gradually over successive IPSPs, reaching a significant plateau level of depression (i.e., one at which no further depression occurred through the remainder of the stimulation train) by the tenth spike in the train $(59 \pm 8 \%$; $p<0.05 ; n=10$; Fig. $1 A$ ). At $10 \mathrm{~Hz}$, the depression did not begin to develop until after the first five spikes, but it again reached a significant plateau level of depression by the tenth spike in the train $(67 \pm 6 \% ; p<0.05 ; n=10$; Fig. $1 B)$. At $20 \mathrm{~Hz}$, the IPSP was initially nonsignificantly facilitated over the first five spikes in the train $(106 \pm 11 \% ; p>0.05)$, a nonsignificant plateau level of depression to $\sim 80 \%$ of control developing between the fifth and tenth spikes in the train $(81 \pm 20 \% ; p>0.1 ; n=10$; Fig. $1 C, D)$. Although the magnitude of the synaptic depression was reduced with an increase in stimulus frequency, there was no significant difference between the plateau level reached at 5 and $10 \mathrm{~Hz}(p>$ 0.05; one-way ANOVA). The plateau level reached at $20 \mathrm{~Hz}$ was significantly different, however, to that at 5 and $10 \mathrm{~Hz}(p<0.001$, one-way ANOVA). Recovery of the depression had usually occurred within 1-2 sec of the end of the stimulus train (Fig. 1D). This pattern of activity-dependent plasticity occurred consistently in all of the CCIN-motor neuron (MN) pairs examined $(n=10)$. The activity-dependent changes of the IPSP amplitude were not associated with a change in the CCIN spike amplitude or duration over the course of the spike train (Fig. 1D), because there was no significant correlation between the amplitude of the IPSP and the spike width $\left(r^{2}=0.087\right)$ or amplitude $\left(r^{2}=0.056\right)$ measured at the soma, (data not shown).

Synaptic inputs from glutamatergic EINs exhibited a similar pattern of activity-dependent plasticity as CCINs. At $5 \mathrm{~Hz}$, the depression again developed gradually during the spike train to reach a final level of $56 \pm 15 \%$ of control $(p<0.05)$, although no clear plateau level was reached. At $10 \mathrm{~Hz}$, a plateau level of depression was reached between the fifth and tenth spikes in the train $(57 \pm 9 \% ; p<0.05)$. At $20 \mathrm{~Hz}$, the monosynaptic EPSP reached a plateau level of depression between the fifth and tenth spikes in the train $(77 \pm 20 \% ; p>0.05 ; n=11$; Fig. 2). The depression that developed was thus again less at higher stimulus frequencies. As with CCIN inputs, there was no significant difference between the level of depression reached at 5 and $10 \mathrm{~Hz}$ ( $p>0.05$; one-way ANOVA), but the plateau reached at $20 \mathrm{~Hz}$ was significantly different to the depression at 5 and $10 \mathrm{~Hz}(p<$ 0.001; one-way ANOVA). Recovery of the depression again usually occurred within 1-2 sec of the end of the stimulus train (Fig. 

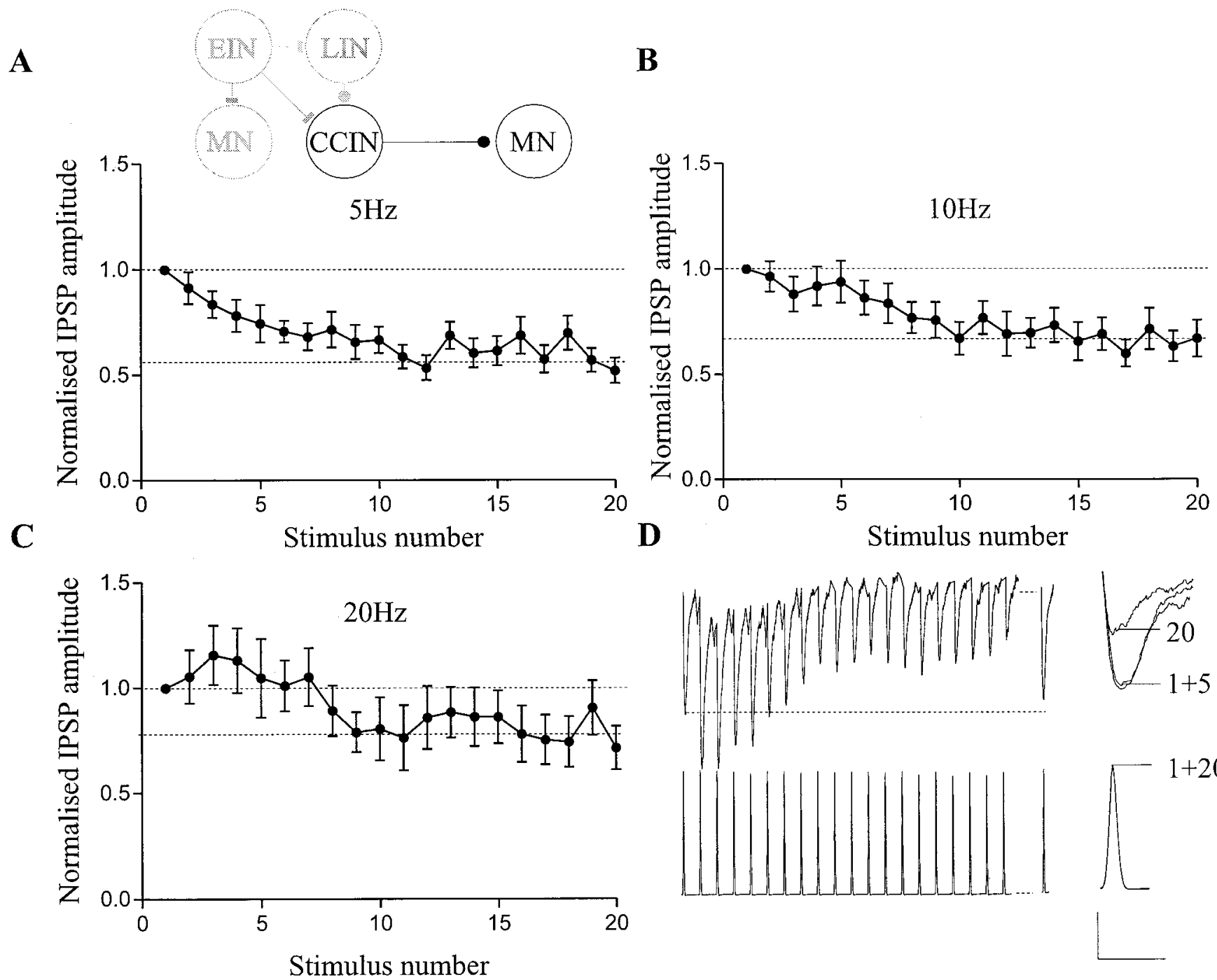

D Stimulus number

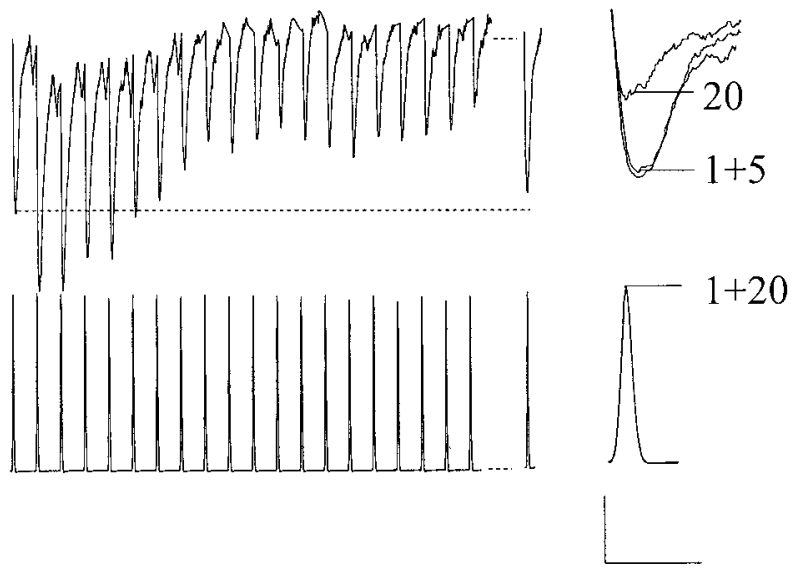

Figure 1. Activity-dependent plasticity of inhibitory CCIN inputs. Effects of $5(A), 10(B)$, and $20(C) \mathrm{Hz}$ stimulation of the presynaptic CCIN on the amplitude of the IPSP recorded in a contralateral motor neuron. In this and subsequent figures, the inset shows a schematic diagram of one segment of the lamprey spinal cord. Filled circles indicate glycinergic connections, bars indicate glutamatergic connections. Inhibitory CCINs inhibit all contralateral neurons. The neurons that are studied on each figure are highlighted. In all figures, IPSP or EPSP values are normalized to the amplitude of the initial PSP in the train. Dashed lines on the graphs indicate the level of the initial IPSP, and, where appropriate, the plateau level of depression reached. $D$, Traces from a motor neuron and a CCIN showing the effects of $20 \mathrm{~Hz}$ stimulation on the amplitude of the monosynaptic IPSP. The dashed line indicates a delay of $1 \mathrm{sec}$ before a test spike was given to measure the extent of the recovery from depression. At the end of each trace, the $1 \mathrm{st}$ and $20 \mathrm{th}$ spike in the train and the 1st, 5th, and 20th IPSP are overlaid on an expanded time scale. Note that there is no activity-dependent effect on the CCIN spike. Summed data from 10 inhibitory CCIN-MN pairs is shown in $A-C$. Calibration: $0.5 \mathrm{mV}$ (for the synaptic input), $30 \mathrm{mV}$ (spikes), $200 \mathrm{msec} ; 0.5 \mathrm{mV}, 20$ msec (for the expanded traces).

$2 D)$. These effects also occurred consistently in the different EIN-MN pairs examined ( $n=10$ of 11 ; Fig. $2 A-C)$, although in one pair a significant plateau level of depression of the EPSP occurred after the first two spikes in the train at $20 \mathrm{~Hz}$ (data not shown). In addition, in some pairs nonsignificant facilitation $(p>$ 0.05 ) could develop during the first five spikes in the train, particularly at higher frequencies $(5 \mathrm{~Hz}, n=3 ; 10 \mathrm{~Hz}, n=2 ; 20$ $\mathrm{Hz}, n=9$; Fig. $2 A-C$ ). As with inhibitory CCINs, no effect on the presynaptic spike was seen over the course of the spike train (Fig. $2 D)$, there again being no correlation between the EPSP amplitude and the somatic spike width $\left(r^{2}=0.091\right)$ or amplitude $\left(r^{2}=\right.$ 0.117; data not shown).

In addition to examining inhibitory CCIN and EIN inputs, the activity-dependent plasticity of two other connections, excitatory CCIN inputs to contralateral motor neurons (Buchanan, 1982) and glycinergic LIN inputs to ipsilateral CCINs (Buchanan, 1982) have also been examined. Excitatory CCIN inputs exhibited a similar pattern of activity-dependent plasticity as inhibitory CCINs (Fig. 3A), although the depression that developed was greater than that seen with inhibitory CCIN inputs $(p<0.001$; one-way ANOVA; Figs. $1 A-C, 3 A$ ). At $5 \mathrm{~Hz}$, depression developed gradually to reach a plateau level between the fifth and tenth spikes in the train $(34 \pm 5 \% ; p<0.01 ; n=4)$. As with inhibitory CCIN and EIN inputs, at $10 \mathrm{~Hz}$ the level of depression reached was less than that at $5 \mathrm{~Hz}(37 \pm 4 \%$; $p<0.01)$; the depression also took longer to reach a plateau level. At $20 \mathrm{~Hz}$ there was again a nonsignificant facilitation over the first three spikes $(104 \pm 9 \%$; $p>0.05$ ), which was followed by depression to $52 \pm 7 \%$ of control $(p<0.01)$. The depression at $20 \mathrm{~Hz}$ did not reach a plateau level, it instead increased continuously during the spike train. There 
A

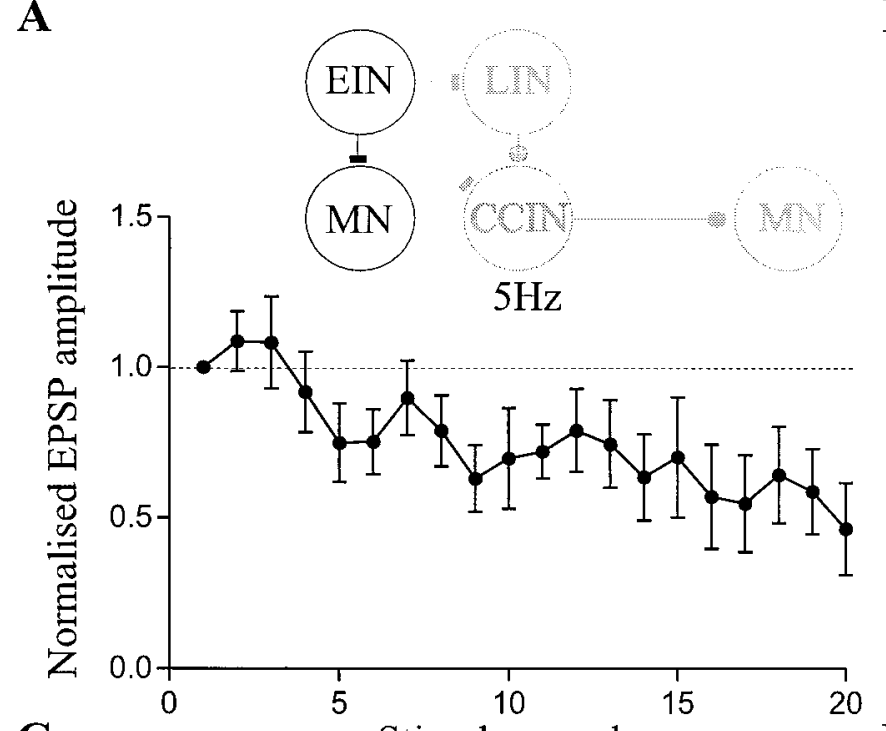

C

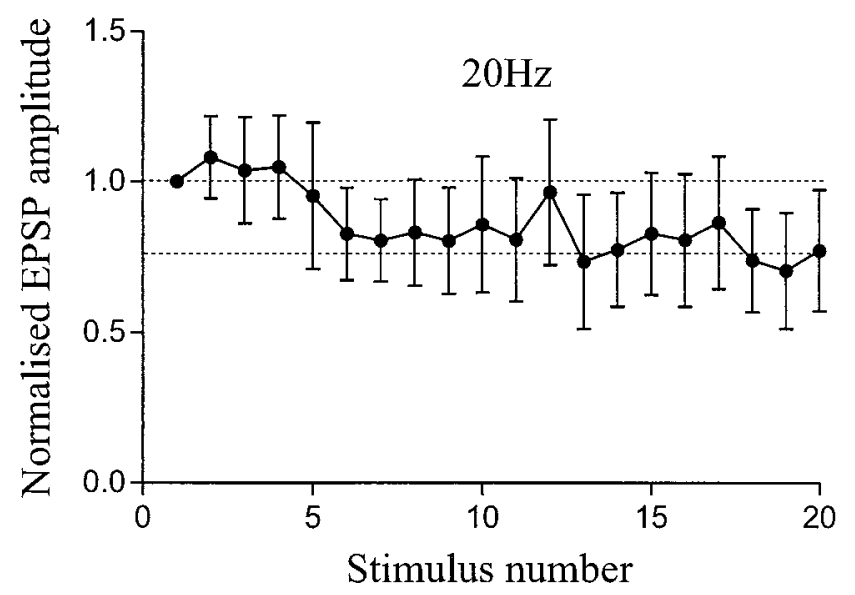

B

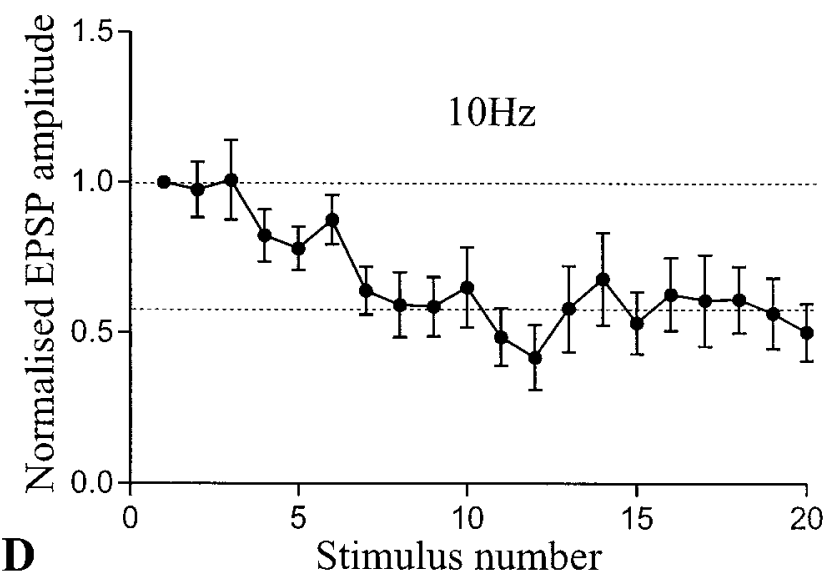

Figure 2. Activity-dependent plasticity of EIN inputs. Effects of $5(A), 10(B)$, and $20(C) \mathrm{Hz}$ stimulation of the presynaptic EIN on the amplitude of the monosynaptic EPSP in an ipsilateral motor neuron (inset). D. Traces from a motor neuron and an EIN showing the effects of $20 \mathrm{~Hz}$ stimulation on the amplitude of the monosynaptic EPSP. The dashed line again indicates a delay of $1 \mathrm{sec}$ before a test spike was given to measure the extent of the recovery from depression. Expanded traces of the 1st and 20th spike in the train and the 1st, 5th, and 20th EPSP are also shown. Note that there is again no activity-dependent effect on the EIN spike. Summed data from $11 \mathrm{EIN}-\mathrm{MN}$ pairs is shown in $A-C$. Calibration: $0.5 \mathrm{mV}$ (for the synaptic input), 30 $\mathrm{mV}$ (spikes), $200 \mathrm{msec} ; 0.5 \mathrm{mV}, 20 \mathrm{msec}$ (for the expanded traces).

was again no significant difference between the plateau level reached at 5 and $10 \mathrm{~Hz}(p>0.05$; one-way ANOVA), whereas the final level at $20 \mathrm{~Hz}$ was significantly different to that at the other two frequencies ( $p<0.001$; one-way ANOVA). With LIN inputs $(n=4)$ at each frequency, a significant plateau level of depression to $50-55 \%$ of control developed between the fifth and tenth spikes in the train $(p<0.01$; Fig. $3 B)$. The plateau level of depression reached was not significantly different for the different stimulation frequencies ( $p>0.05$; one-way ANOVA), although the depression developed faster at lower stimulation frequencies (Fig. 3B).

Significant activity-dependent synaptic plasticity of inputs from identified network interneurons thus develops during physiological spike trains. However, with the exception of excitatory CCIN and LIN inputs at 5 and $10 \mathrm{~Hz}$, and inhibitory CCIN inputs at 5 $\mathrm{Hz}$, significant activity-dependent plasticity only occurred in the latter part of the spike train, typically between the fifth and tenth spikes. Because network interneurons have been reported to fire up to five spikes during locomotor activity (Buchanan and Cohen, 1982; Buchanan and Kasicki, 1995), the activity-dependent plasticity that develops after this time will presumably only be relevant when network interneurons fire relatively long bursts of action potentials, and thus will presumably not contribute significantly to the patterning of network activity during the normal range of locomotor frequencies.

\section{Effects of neuromodulators on the induction of activity-dependent plasticity}

Neuromodulators can profoundly alter the output of the lamprey locomotor network (see Harris-Warrick and Cohen, 1985; Parker et al., 1998). This network modulation is associated with changes in the cellular and synaptic properties of network neurons (Wallén et al., 1989; Parker and Grillner, 1998). Because synaptic plasticity is itself plastic (metaplasticity; Abraham and Bear, 1996), the effects of two neuromodulators, 5-HT and substance P, which have been studied in detail on the locomotor network 

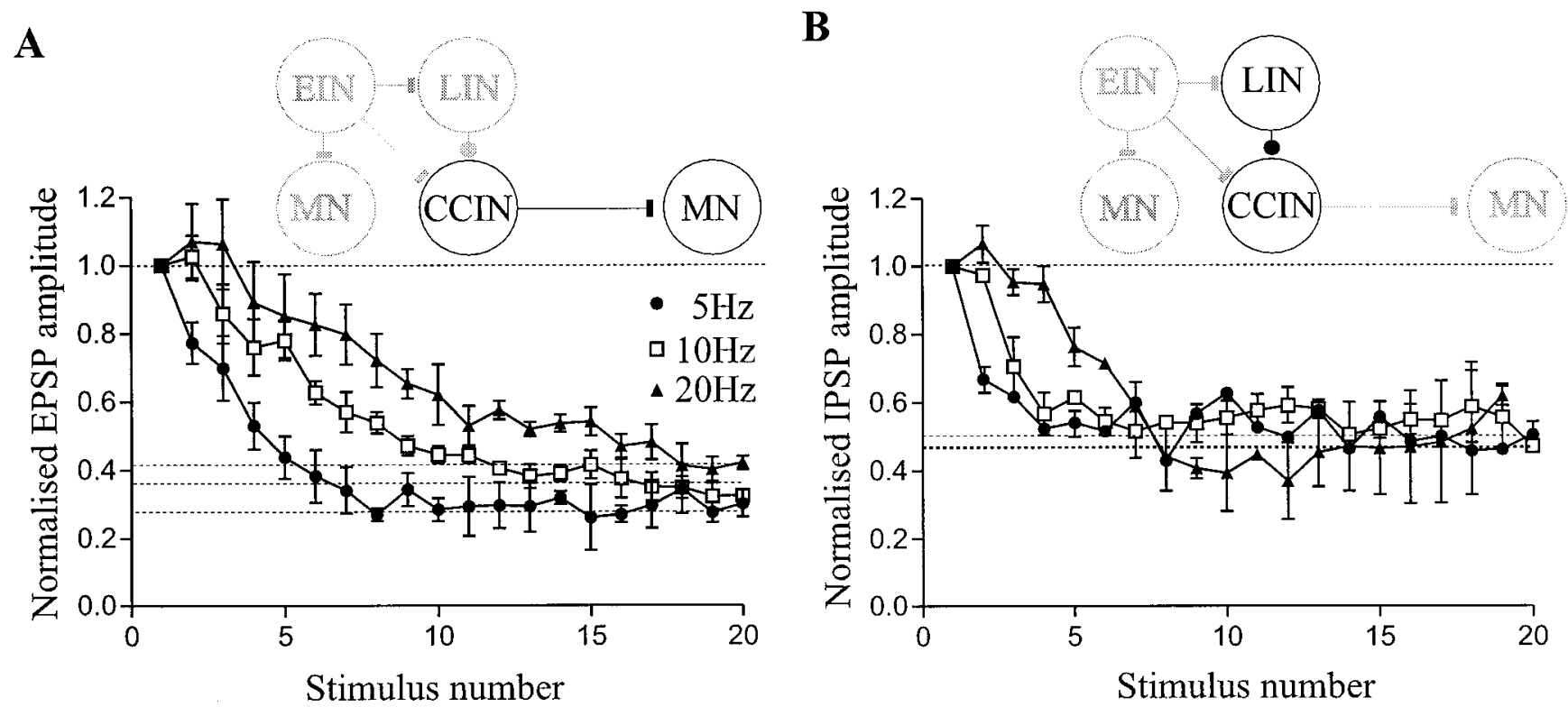

Figure 3. Activity-dependent plasticity of excitatory CCIN and LIN inputs. $A$, Effects of 5, 10, and $20 \mathrm{~Hz}$ stimulation of presynaptic excitatory CCINs on the amplitude of the monosynaptic EPSP in a contralateral motor neuron (inset). B, Effects of 5, 10, and $20 \mathrm{~Hz}$ stimulation of the presynaptic LIN on the amplitude of the monosynaptic IPSP in an ipsilateral CCIN (inset). Summed data from four pairs is shown on each graph.

(Harris-Warrick and Cohen, 1985; Wallén et al., 1989; Parker and Grillner, 1998; Parker et al., 1998), were examined to determine whether modulation of the network output could be associated with the metaplasticity of interneuron inputs. Neuromodulators were studied on EIN and inhibitory CCIN inputs because these interneurons are thought to be of primary importance in the patterning of network activity (Hellgren et al., 1992). The tachykinin substance P (1 $\mu \mathrm{M}$; Parker and Grillner, 1998; Parker et al., 1998) did not affect the amplitude of the first CCIN-evoked IPSP in the train compared with control (Fig. 4Di), consistent with its failure to modulate the amplitude of single, low frequency-evoked inhibitory CCIN inputs (Parker and Grillner, 1998). Substance P also did not significantly affect the depression of CCIN inputs that developed during $5 \mathrm{~Hz}$ stimulation ( $p>0.1 ; n=5$; Fig. $4 A$ ). However, it significantly enhanced the depression of the monosynaptic IPSP at 10 and $20 \mathrm{~Hz}(p<0.05 ; n=5$; Fig. 4B,C,E). Substance P reduced the IPSP amplitude to $16 \pm 9 \%$ of control after the first three spikes in the train at $20 \mathrm{~Hz}$ (Fig. 4C, Di, E) and to $45 \pm 8 \%$ at $10 \mathrm{~Hz}$ (Fig. $4 B, E$ ). Although the depression was enhanced by substance $\mathrm{P}$, the amplitude of the IPSP still usually recovered within 1-2 sec of the end of the stimulation train (data not shown). As with substance P, 5-HT (10 $\mu \mathrm{M})$ had no consistent or significant effect on the amplitude of the initial CCIN-evoked IPSP in the train compared with control (Fig. 4Dii). However, in contrast to substance P, 5-HT facilitated the amplitude of CCIN inputs at 5, 10, and $20 \mathrm{~Hz}$ to $\sim 150 \%$ of control over the first five spikes in the train $(p<0.05 ; n=4$; Fig. $4 A-C, D i i)$. Although the magnitude of the facilitation was not significantly different at the different frequencies ( $p>0.1$; one-way ANOVA), its duration differed, in that it was maintained throughout the stimulation train at $5 \mathrm{~Hz}$, recovered to control after ten spikes at $10 \mathrm{~Hz}$, and developed into a depression of $\sim 60 \%$ of control after the first five spikes at $20 \mathrm{~Hz}$ (Fig. 4A-C, E).

Low frequency-evoked EIN inputs are potentiated by substance P (1 $\mu \mathrm{M}$; Parker and Grillner, 1998), and consequently substance $\mathrm{P}$ increased the amplitude of the initial EPSP in the train compared with control (Fig. 5Di). In addition to increasing the amplitude of the initial EPSP, substance $\mathrm{P}$ nonsignificantly reduced the depression of the EPSP at 5 and $10 \mathrm{~Hz}(p>0.05 ; n=$ 5; Fig. $5 A, B)$. However, at $20 \mathrm{~Hz}$, substance $\mathrm{P}$ caused significant facilitation of the EPSP amplitude ( $p<0.05 ; n=5$; Fig. $4 C$ ), which was maintained throughout the stimulation train (Fig. $5 C, D i, E)$. In contrast to substance P, 5-HT $(10 \mu \mathrm{M})$ markedly depressed the amplitude of the initial EPSP in the train (30 \pm $12 \% ; p<0.01 ; n=5$; Fig. 5Dii). As with substance P, 5-HT (10 $\mu \mathrm{M})$ failed to significantly affect the depression of the EPSP amplitude at $5 \mathrm{~Hz}(p>0.05 ; n=5$; Fig. $5 A)$ but caused significant facilitation of the EPSP amplitude at 10 and $20 \mathrm{~Hz}$ $(p<0.05 ; n=5$; Fig. $5 B, C)$. Although the magnitude of the effect was greatest at $10 \mathrm{~Hz}$, the facilitation had decayed to control by the end of the spike train, whereas at $20 \mathrm{~Hz}$ it was maintained throughout the spike train (Fig. $5 E$ ). The facilitation of EIN inputs evoked by substance $\mathrm{P}$ and 5-HT again usually recovered within 1-2 sec of the end of the stimulation train (data not shown). The metaplasticity of EIN and inhibitory CCIN synaptic inputs was not associated with an effect on the spike amplitude or duration (CCIN: substance P, spike amplitude $r^{2}=0.14$, spike duration $r^{2}=0.11$; 5-HT: spike amplitude $r^{2}=0.12$, spike duration $r^{2}=0.16$; EIN: substance P, spike amplitude $r^{2}=0.17$, spike duration $r^{2}=0.09$; and 5-HT: spike amplitude $r^{2}=0.14$, spike duration $r^{2}=0.21$ ). It was not possible to maintain recordings from EINs long enough to examine recovery of the metaplastic effects of 5-HT of substance P, but in CCINs, the effects of 5-HT $(n=3$ of 5$)$ and substance $\mathrm{P}(n=3$ of 5$)$ had partially recovered after washing for between 1-2 hr (data not shown).

\section{The substance P-evoked metaplasticity of EIN inputs is not NMDA-dependent}

The substance P-mediated potentiation of single low frequencyevoked EIN inputs is caused by an increase in transmitter release and the postsynaptic potentiation of NMDA, but not AMPA, receptors (Parker and Grillner, 1998; Parker et al., 1998). To determine whether the potentiation of NMDA responses could contribute to the facilitation of EIN inputs during the spike train, 
A

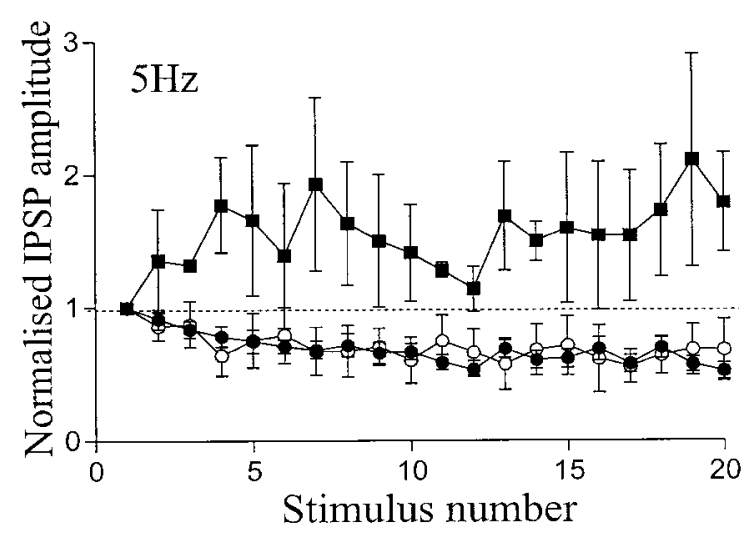

B

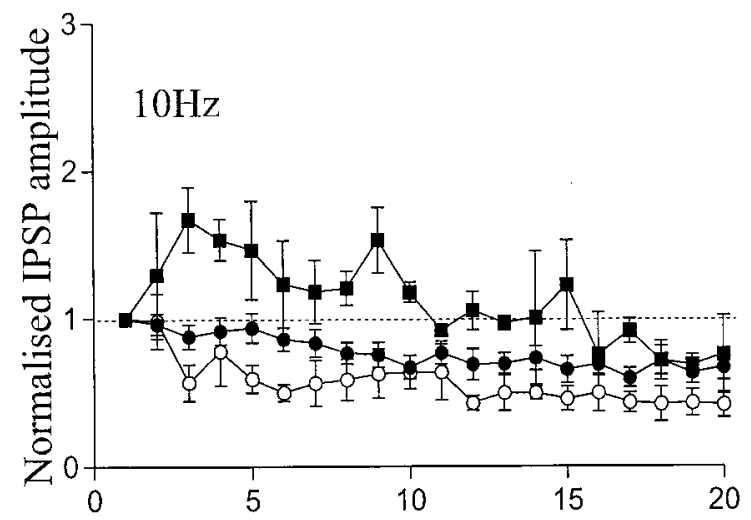

C

Stimulus number

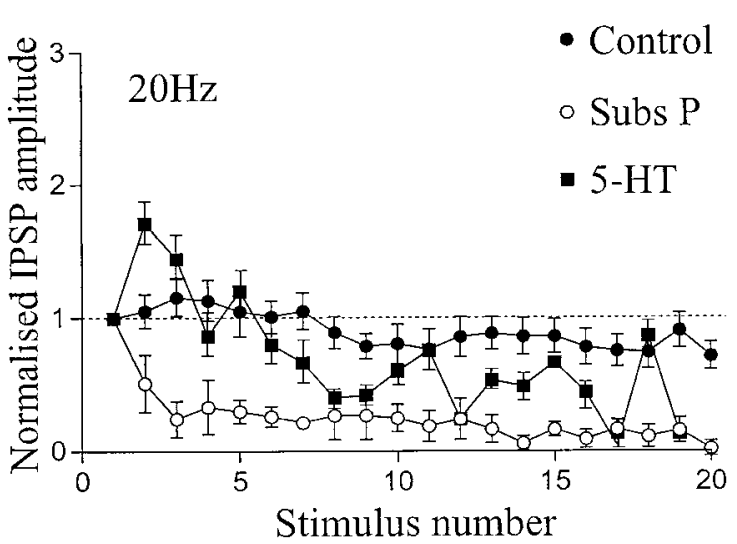

Di

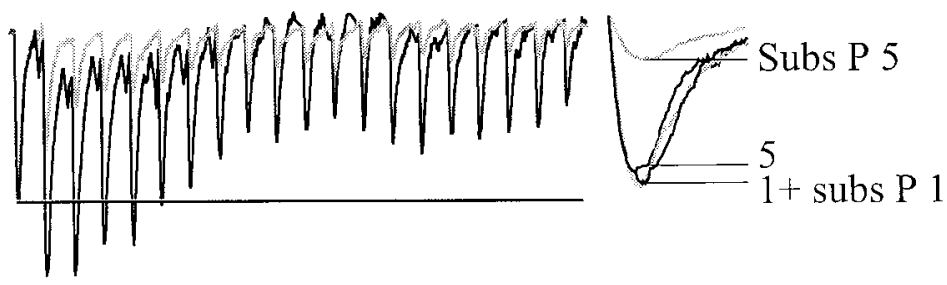

Dii

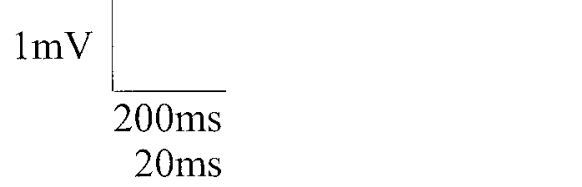

E

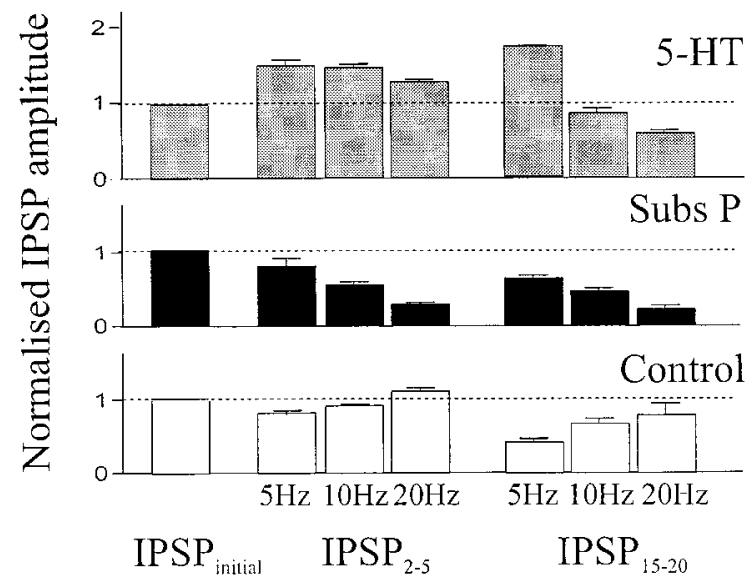

Figure 4. Metaplasticity of inhibitory CCIN-evoked inputs. Graphs showing the effects of $5(A), 10(B)$, and $20(C) \mathrm{Hz}$ stimulation of CCINs on monosynaptic inputs to contralateral motor neurons. Because the pattern of activity-dependent plasticity seen in this study occurred consistently, control responses before application of the neuromodulators were similar. Thus, control responses before substance $\mathrm{P}$ and 5-HT application are combined on the graphs to simplify comparison of their effects (substance P, $1 \mu \mathrm{M} ; \bigcirc ; n=5 ; 5$-HT, $10 \mu \mathrm{M} ; \mathbf{\square} ; n=4$ ). Di, Traces showing the effects of $20 \mathrm{~Hz}$ stimulation on the CCIN input to a contralateral motor neuron in control (black line) and in the same cell after the application of $1 \mu \mathrm{M}$ substance P ( gray line). At the end of trace, the 1st and 5th IPSPs in a train from a different experiment are shown on an expanded time scale in control (black line) and in the presence of substance P (gray line). Dii, Traces showing the effects of $5 \mathrm{~Hz}$ stimulation on the CCIN input (black line) and in the same cell after application of $10 \mu \mathrm{M}$ 5-HT (gray line). The 1st and 5th IPSPs from a separate experiment are again shown in control (black line) and in the presence of 5-HT (gray line). Horizontal lines in Di and Dii indicate the amplitude of the initial IPSP in control (black line) and in substance P or 5-HT (gray line), the overlap of the lines indicating that there was no effect of 5-HT on the amplitude of the initial IPSP in the train. $E$, Graph showing the effects of stimulus trains at $5-20 \mathrm{~Hz}$ on CCIN IPSPs. Averages of the first IPSP in the train (IPSP initial $_{1}$, IPSPs during the early part of the train (IPSP $\left.{ }_{2-5}\right)$, and the final five IPSPs in the train $\left(I P S P_{15-20}\right)$ are shown at each frequency in control and in the presence of substance P $(1 \mu \mathrm{M})$ or $5-\mathrm{HT}(10 \mu \mathrm{M})$. Calibration: $1 \mathrm{mV}, 200 \mathrm{msec}$ (for the train), $20 \mathrm{msec}$ (for the expanded trace).

the effects of substance P on EIN inputs were examined in the presence of the NMDA receptor antagonist AP-5 (100 $\mu \mathrm{M})$. Although AP-5 reduced the amplitude of the initial EPSP to $80 \%$ of control (data not shown), it did not affect the pattern of activity-dependent plasticity evoked in control at $5-20 \mathrm{~Hz}$ (Fig. $6 A i)$ or the substance P-mediated facilitation of EIN inputs during $20 \mathrm{~Hz}$ stimulation $(n=4$; Fig. $6 A i, A i i)$. The metaplasticity of EIN inputs by substance $P$ thus does not appear to involve the 
A

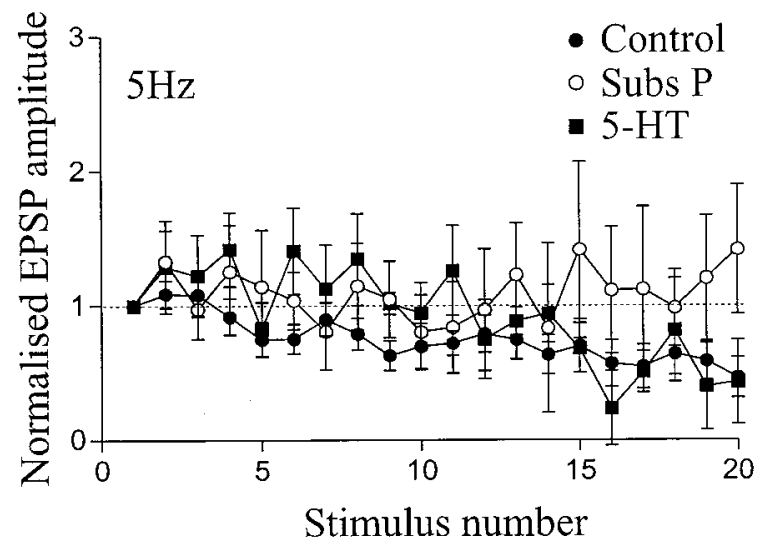

B

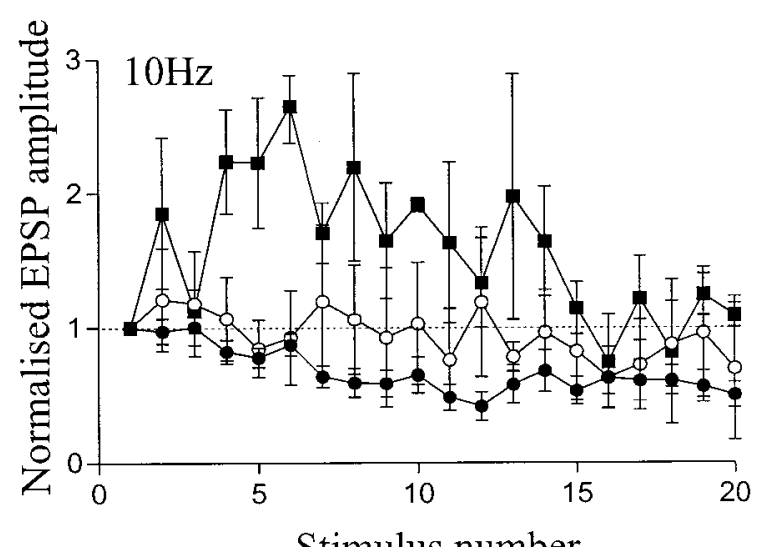

C

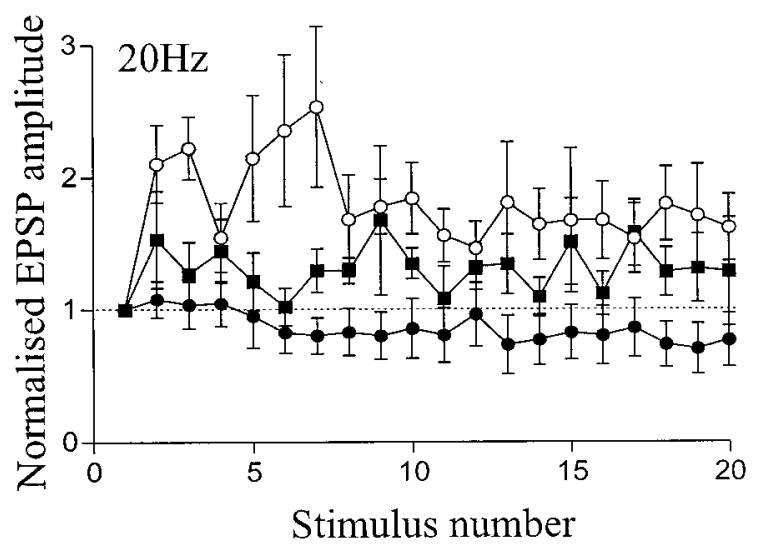

Di

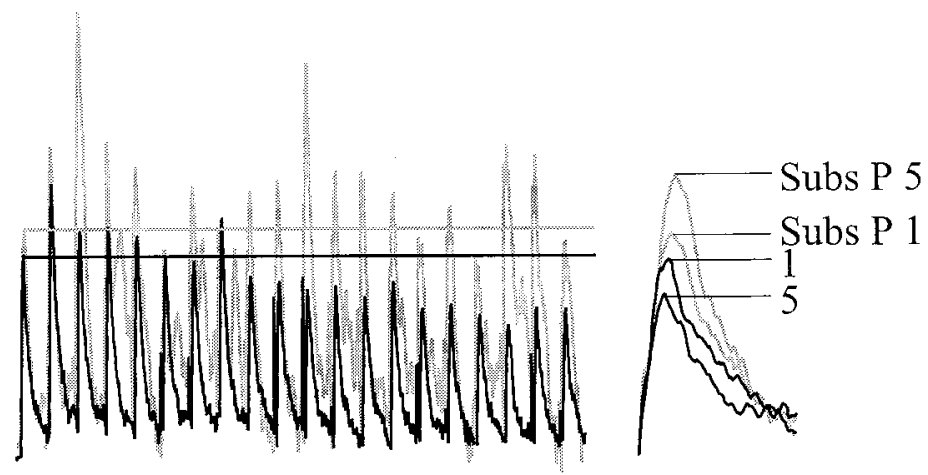

Dii
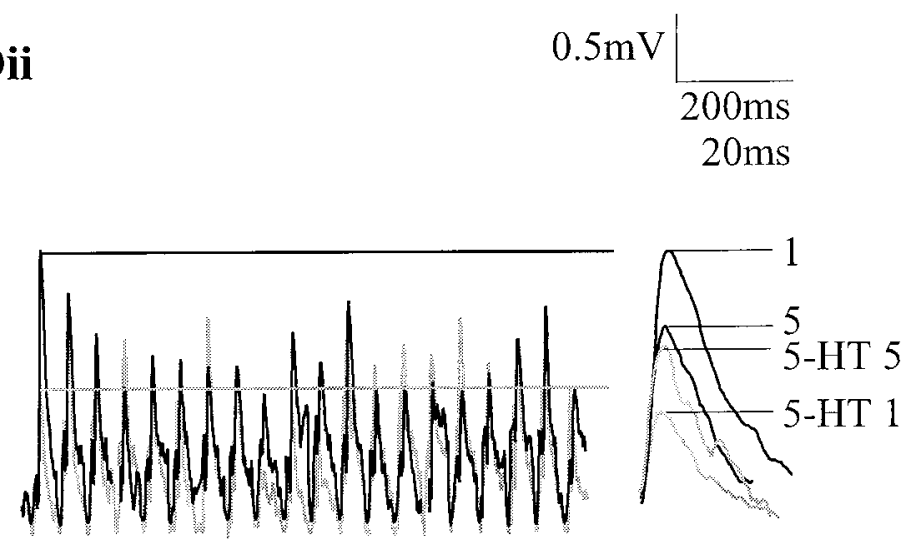

E

5-HT

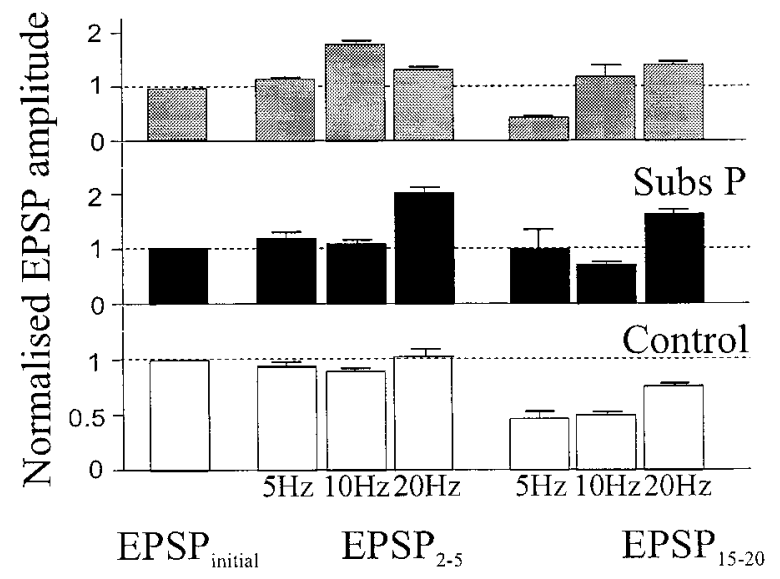

Figure 5. Activity-dependent plasticity and metaplasticity of excitatory synaptic inputs. Graphs showing the effects of $5(A), 10(B)$, and $20(C) \mathrm{Hz}$ stimulation of EINs on monosynaptic inputs in contralateral motor neurons. As in Figure 4, because the pattern of activity-dependent plasticity in control was similar, summed control data from EIN to motor neuron pairs before substance $\mathrm{P}(1 \mu \mathrm{M} ; \bigcirc ; n=5)$ and 5 -HT (10 $\mu \mathrm{M}$; $\mathbf{\square} ; n=5)$ application are shown on the graphs. $D i$, Traces showing EIN inputs to a postsynaptic ipsilateral motor neuron at $20 \mathrm{~Hz}$ in control (black line) and the modulation of the effects by $1 \mu \mathrm{M}$ substance P (gray line). The 1st and 5th EPSPs in a train from a different experiment to that in $D i$ are also shown on an expanded time scale in control (black line) and in the presence of substance P ( gray line). Dii, Traces showing plasticity of EIN inputs evoked at $20 \mathrm{~Hz}$ in control (black line) and its modulation by $10 \mu \mathrm{M} 5-\mathrm{HT}$ (gray line). The 1st and 5th EPSPs in a train from a different experiment to that in Di are also shown on an expanded time scale in control (black line) and in the presence of 5-HT (gray line). The horizontal lines on the traces in Di and Dii indicate the amplitude of the initial EPSP in control (black) and in substance P or 5-HT (gray). E, Graph showing the effects of stimulus trains at 5-20 Hz on EIN-evoked EPSPs. The first EPSP in the train $\left(E P S P_{\text {initial }}\right)$, EPSPs during the early part of the train $\left(E P S P_{2-5}\right)$, and during the final five EPSPs in the train $\left(E P S P_{15-20}\right)$ are shown. These effects are shown for control cords, and in the presence of substance P $(1 \mu \mathrm{M})$ or 5 -HT (10 $\left.\mu \mathrm{M}\right)$. Calibration: $0.5 \mathrm{mV}$, $200 \mathrm{msec}$ (for the train), $20 \mathrm{msec}$ (for the expanded trace). 
Ai

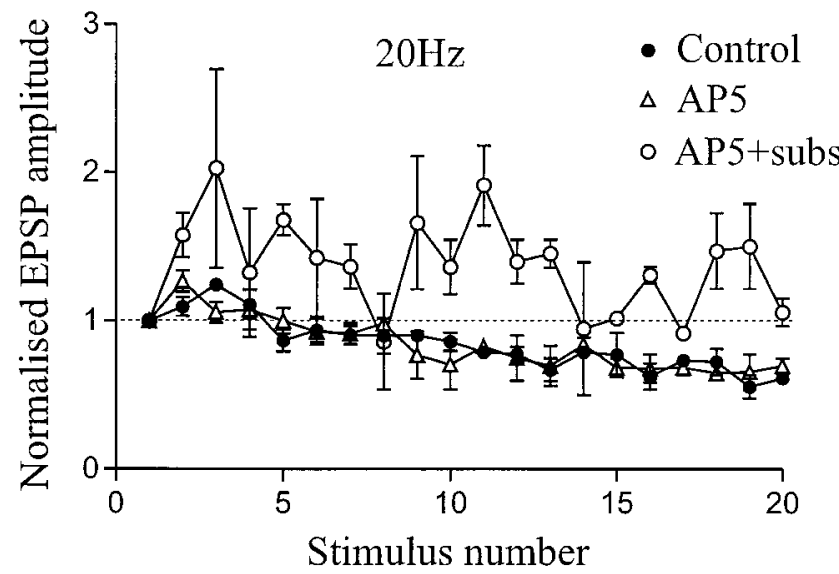

B

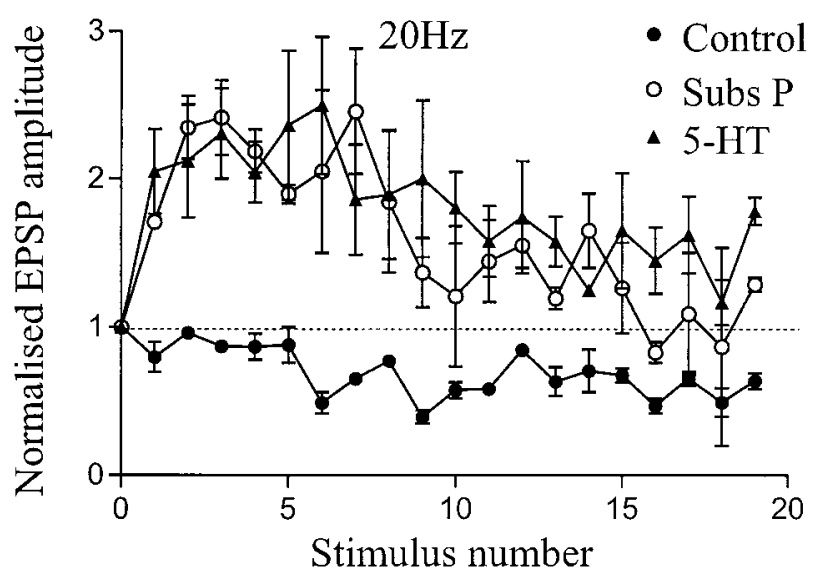

modulation of NMDA receptors. Although the actual mechanism remains to be examined, 5-HT and substance $\mathrm{P}$ appear to share a common mechanism at some point, because previous application of substance $\mathrm{P}$ occluded the facilitating effect of 5-HT on EIN inputs $(n=3$; Fig. $6 B)$.

\section{DISCUSSION}

The results of this study show that synaptic inputs from identified interneurons in the lamprey spinal cord exhibit activitydependent plasticity during spike trains at physiological frequencies and that the induction and expression of this plasticity can be altered by neuromodulators, thus providing examples of metaplasticity (Abraham and Bear, 1996; Fischer et al., 1997).

Although interneuron inputs exhibited activity-dependent depression during spike trains at physiological frequencies, significant depression of EIN and CCIN inputs, which are thought to be of central importance to the patterning of network activity (Hellgren et al., 1992), usually occurred between the fifth and tenth spikes in the train, the only exception being inhibitory CCIN inputs evoked at $5 \mathrm{~Hz}$, which were significantly depressed by the third spike in the train. Because these network neurons typically fire bursts of up to 5 spikes at frequencies of $5-30 \mathrm{~Hz}$ during the normal frequency range of network activity $(0.5-10 \mathrm{~Hz}$; Buchanan and Cohen, 1982; Buchanan and Kasicki, 1995), activity-dependent changes of synaptic inputs from these interneurons will presumably only contribute to the regulation of network activity when interneurons fire longer spike trains, as
Aii

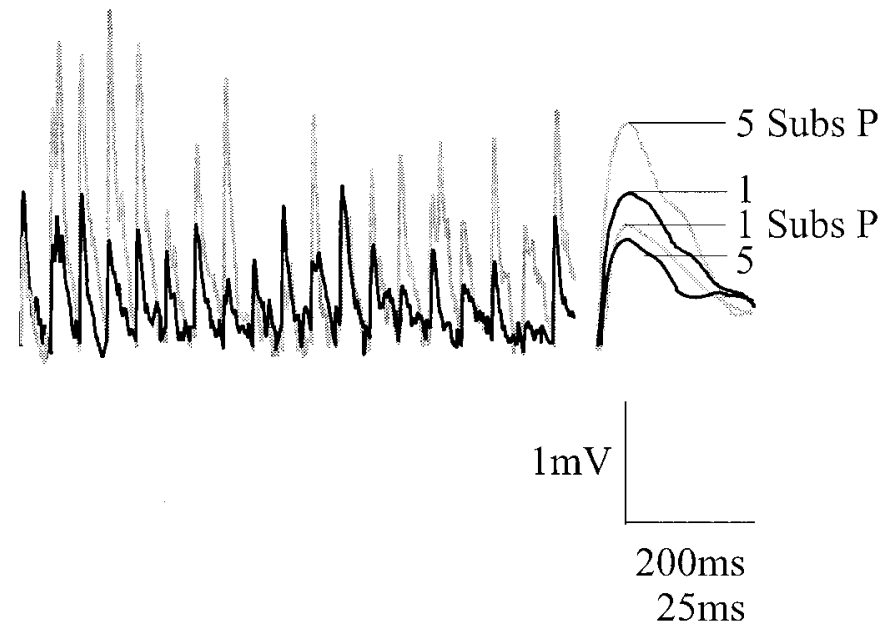

Figure 6. The substance P-mediated metaplasticity of EIN inputs is not NMDA-dependent. $A i$, Graph showing the effects of $20 \mathrm{~Hz}$ stimulation of EINs on the amplitude of the monosynaptic EPSP in ipsilateral motor neurons. The pattern of the activity-dependent plasticity and the substance P-evoked metaplasticity of EIN inputs was not affected when examined in the presence of the NMDA receptor antagonist AP-5 (100 $\mu \mathrm{M})$. Data from four pairs is shown on this graph. Aii, Traces showing EIN inputs after $20 \mathrm{~Hz}$ stimulation in the presence of AP-5 (100 $\mu \mathrm{M}$; black line $)$ and in the presence of AP-5 and substance $\mathrm{P}(1 \mu \mathrm{M}$; gray line $)$. At the end of trace, the 1st and 5th EPSPs in a train from a different experiment are shown on an expanded time scale in control (black line) and in the presence of substance $\mathrm{P}$ and AP-5 (gray line). $B$, Graph showing the lack of effect of 5-HT $(10 \mu \mathrm{M})$ on EIN inputs already potentiated by $1 \mu \mathrm{M}$ substance P. Data from three pairs is shown in $B$.

may occur during slower locomotor activity or postural changes. In contrast, inputs from excitatory CCINs and LINs showed significant depression over the first five spikes in the train at 5 and $10 \mathrm{~Hz}$. Although the role of these interneurons in network activity have either not been studied or are uncertain, activitydependent plasticity of their inputs may also contribute to the patterning of network activity.

The mechanisms underlying the activity-dependent or metaplastic changes have not yet been examined. The depression that was evoked in each type of interneuron was greater at lower stimulus frequencies. This result suggests against transmitter depletion as a mechanism underlying the synaptic depression, because the depression would be expected to increase with increasing stimulation frequencies (Parker, 1995a). It is possible, however, that partial replenishment of releasable transmitter stores during higher stimulation frequencies contributes to the effects seen (Wang and Kaczmarek, 1998).

The pattern of activity-dependent plasticity of interneuron inputs in this study was consistent across all of the pairs examined. This is in contrast to the situation in other systems, in which variability in the strength of synaptic inputs has been shown (see Markram et al., 1998 and references therein). With the exception of the LINs, all of the experiments reported here used motor neurons as postsynaptic targets, and in all cases, the presynaptic interneurons were recorded in either the same segment, or at most one segment rostral to the postsynaptic neuron. Because 
populations of interneurons will presumably act together to pattern activity in any one segment, it may be expected that the pattern of activity-dependent synaptic inputs examined here will not be markedly different. However, the input from these interneurons to other postsynaptic targets, for example to other network interneurons, or to postsynaptic neurons located more rostrally or caudally, may exhibit differences in the pattern and expression of activity-dependent changes that may be relevant to the coordination of network activity at the segmental or intersegmental level.

\section{Neuromodulator-mediated metaplasticity}

Although significant activity-dependent plasticity of EIN and inhibitory CCIN inputs did not occur during the first five spikes in control conditions, the situation was very different when 5-HT or substance P was applied. 5-HT evoked activity-dependent facilitation of EIN and inhibitory CCIN inputs, whereas substance P evoked activity-dependent facilitation of EIN inputs but enhanced the activity-dependent depression of inhibitory CCINevoked IPSPs. Identified network interneuron inputs thus exhibit neuron and modulator-specific metaplasticity (Abraham and Bear, 1996; Fischer et al., 1997). In contrast to the activitydependent changes in control, these metaplastic effects were pronounced over the initial part of the spike train and can thus presumably contribute to the modulation of the network output during the normal frequency range of locomotor activity.

The substance P and 5-HT-mediated metaplasticity of inhibitory CCIN inputs is consistent with the effects of these modulators on the network output, namely an increase and a decrease, respectively, in the frequency of network activity (HarrisWarrick and Cohen, 1985; Parker et al., 1998). The substance P-mediated depression of CCIN inputs during the spike train will reduce the strength of reciprocal inhibitory drive during network activity. This will allow the contralateral network to escape from inhibition earlier, thus resulting in an increase in the frequency of network activity (Hellgren et al., 1992). In contrast, 5-HT facilitated inhibitory CCIN inputs. This will increase the strength of reciprocal inhibitory drive during the CCIN burst, delaying the onset of activity in the contralateral network, and thus reducing the frequency of network activity (Hellgren et al., 1992). The substance $\mathrm{P}$ and 5-HT-mediated metaplasticity of inhibitory CCIN inputs is thus consistent with the effects of these modulators on the network output.

Substance P and 5-HT both facilitated EIN inputs during the spike train. Their effects differed, however, in that substance $P$ facilitates the amplitude of single low frequency-evoked EIN inputs (Parker and Grillner, 1998) and thus increased the amplitude of the initial EPSP in the train compared with control. 5-HT, however, markedly depressed the amplitude of the initial EPSP in the train compared with control. Thus, the facilitation of EIN inputs evoked by substance $\mathrm{P}$ develops from an initial potentiation of the EPSP amplitude, whereas the 5-HT-mediated facilitation develops from a marked reduction of the EIN input. The net effect is that substance $P$ potentiates EIN inputs during the train compared with control (Fig. 5Di), whereas in the presence of 5-HT, EIN inputs during the train are not significantly affected compared with control (Fig. 5Dii). At the network level, increasing the general level of excitation results in an increase in the frequency of network activity both experimentally (Brodin et al., 1985) and in computer simulations (Hellgren et al., 1992), although specifically potentiating EIN inputs to CCINs slows simulated network activity (Hellgren et al., 1992). Thus, although the increase in excitatory drive is consistent with the effects of substance $\mathrm{P}$ on the network output, the metaplasticity of EIN inputs to other network components will need to be examined.

\section{Contribution of cellular and synaptic mechanisms to the modulation of the network output}

Both cellular and synaptic mechanisms can contribute to the patterning and modulation of network activity (Marder and Calabrese, 1996; Marder et al., 1996), and thus individual cellular or synaptic effects should not be taken in isolation in an attempt to explain the mechanisms underlying network modulation. In addition to examining the modulatory effects of substance $\mathrm{P}$ on synaptic transmission, its effects have previously been studied in detail on identified network interneurons at the cellular level (Parker and Grillner, 1998). Substance P increases the excitability of EINs, and this effect could act to increase EIN spiking during network activity from lower frequencies, where there is a nonsignificant potentiation of EIN inputs in the presence of substance $\mathrm{P}$, to higher frequencies, where there is a significant potentiation of EIN inputs. Thus, cellular and synaptic effects of substance P may act in parallel to facilitate EIN inputs, and thus excitatory drive to the network. In contrast to its effects on EINs, substance $P$ reduces the excitability of CCINs (Parker and Grillner, 1998), an effect that will again act in parallel with the enhanced depression of IPSPs during the train to reduce the strength of reciprocal inhibitory drive. Because the greatest activity-dependent depression of CCIN inputs occurred at higher frequencies, there will be a window of CCIN spiking frequencies between $10-20 \mathrm{~Hz}$ at which significant activity-dependent depression will occur in parallel with a substance P-mediated reduction in the number and frequency of CCIN spikes (Parker and Grillner, 1998). Thus, substance $\mathrm{P}$ has complementary modulatory effects on the cellular and synaptic properties of EINs and CCINs. Depending on the circumstances, these effects could act synergistically or independently to modulate the frequency of network activity.

\section{Summary}

In summary, the results of this study suggest that activitydependent plasticity of synaptic transmission from inhibitory CCINs and EINs plays little role in patterning network activity under control conditions during locomotion. However, because interneuron inputs to motor neurons have only been examined here, further work is needed before concluding that activitydependent plasticity of these interneuron inputs plays no role in patterning network activity, because it is possible that significant activity-dependent plasticity of these inputs occurs onto other network interneurons, as occurs for LIN inputs to ipsilateral CCINs. Interneuron connections will need to be examined directly, because it is not possible to extrapolate the synaptic input from a single neuron to different postsynaptic targets (see Markram et al., 1998 and references therein; Parker, 1995b). Inputs from CCINs and EINs, however, do exhibit activitydependent metaplasticity, an alteration in the induction of the plasticity by neuromodulators. These effects can be related directly to the modulation of the network output during locomotor activity. Thus, activity-dependent plasticity and metaplasticity need to be considered as additional potential mechanisms underlying the coordination and modulation of rhythmic network activity.

\section{REFERENCES}

Abraham WC, Bear MF (1996) Metaplasticity: the plasticity of synaptic plasticity. Trends Neurosci 19:126-130. 
Brodin L, Grillner S, Rovainen CM (1985) $N$-methyl-D-aspartate (NMDA), kainate and quisqualate receptors and the generation of fictive locomotion in the lamprey spinal cord. Brain Res 325:302-306.

Buchanan JT (1982) Identification of interneurons with contralateral, caudal axons in the lamprey spinal cord: synaptic interactions and morphology. J Neurophysiol 47:961-975.

Buchanan JT (1993) Electrophysiological properties of identified classes of lamprey spinal neurons. J Neurophysiol 70:2313-2325.

Buchanan JT, Cohen AH (1982) Activities of identified interneurons, motoneurons and muscle fibres during fictive swimming in the lamprey and effects of reticulospinal and dorsal cell stimulation. J Neurophysiol 47:948-960.

Buchanan JT, Grillner S (1987) Newly identified "glutamate interneurons" and their role in locomotion in the lamprey spinal cord. Science 236:312-314.

Buchanan JT, Grillner S (1991) 5-hydroxytryptamine depresses reticulospinal excitatory postsynaptic potentials in motoneurones of the lamprey. Neurosci Lett 112:71-74.

Buchanan JT, Kasicki S (1995) Activities of spinal neurons during brain stem-dependent fictive swimming in lamprey. J Neurophysiol 73:80-87.

Calabrese RL (1995) Half-center oscillators underlying rhythmic movements. In: The handbook of brain theory and neural networks (Arbib MA, ed). Cambridge, MA: MIT.

El Manira A, Zhang W, Svensson E, Bussieres N (1997) 5-HT inhibits calcium current and synaptic transmission from sensory neurons in lamprey. J Neurosci 17:1786-1794.

Fischer TM, Blazis DEJ, Priver NA, Carew TJ (1997) Metaplasticity at identified inhibitory synapses in Aplysia. Nature 389:860-865.

Grillner S, Wallén P (1980) Does the central pattern generator for locomotion in lamprey depend on glycine inhibition. Acta Physiol Scand 110:103-105.

Harris-Warrick RM, Cohen AH (1985) Serotonin modulates the central pattern generator for locomotion in the isolated lamprey spinal cord. $\mathrm{J}$ Exp Biol 116:27-46.

Hellgren J, Grillner S, Lansner A (1992) Computer simulation of the segmental neural network generating locomotion in lamprey by using populations of network interneurons. Biol Cybern 68:1-13.
Kiehn O, Hounsgaard J, Sillar KT (1997) Basic building blocks of vertebrate central pattern generators. In: Neurons, networks, and motor behaviour (Stein PSG, Grillner S, Selverston AI, Stuart DG, eds). Cambridge, MA: MIT.

Marder E, Calabrese RL (1996) Principles of rhythmic motor pattern generation. Physiol Rev 76:687-717.

Marder E, Abbott LF, Turrigiano G, Liu Z, Golowasch J (1996) Memory from the dynamics of intrinsic membrane currents. Proc Natl Acad Sci USA 93:13481-13486.

Markram H, Wang Y, Tsodyks M (1998) Differential signaling via the same axon of neocortical pyramidal neurons. Proc Natl Acad Sci USA 95:5323-5328.

Milner B, Squire LR, Kandel ER (1998) Cognitive neuroscience and the study of memory. Neuron 20:445-468.

Parker D (1995a) Depression of synaptic connections between identified motor neurons in the locust. J Neurophysiol 74:529-538.

Parker D (1995b) Long-lasting potentiation of a direct central connection between identified motor neurons in the locust. Eur J Neurosci 7:1097-1106.

Parker D, Grillner S (1998) Cellular and synaptic modulation underlying substance P-mediated plasticity of the lamprey locomotor network. J Neurosci 18:8095-8110.

Parker D, Zhang W, Grillner S (1998) Substance P modulates NMDA responses and causes long-term protein synthesis-dependent modulation of the lamprey locomotor network. J Neurosci 18:4800-4813.

Singer W (1993) Synchronization of cortical activity and its putative role in information processing and learning. Annu Rev Physiol 55:349-374.

Sombati S, Hoyle G (1984) Central nervous sensitization and dishabituation of reflex action in an insect by the neuromodulator octopamine. J Neurobiol 15:455-480.

Wallén P, Buchanan JT, Grillner S, Hill RH, Christenson J, Hökfelt T (1989) Effects of 5-hydroxytryptamine on the afterhyperpolarisation, spike frequency regulation and oscillatory membrane properties in lamprey spinal cord nerves. J Neurophysiol 61:759-768.

Wang L-Y, Kaczmarek LK (1998) High-frequency firing helps replenish the readily releasable pool of synaptic vesicles. Nature 394:384-388. 